\title{
Risk factor identification and evaluation on SPB shield underneath existing railroad settlement
}

Hongde Wang ( $\nabla$ whd@djtu.edu.cn )

Dalian Jiaotong University

\section{Zhaohe Guan}

Dalian Jiaotong University

Shitong He

Dalian Jiaotong University

\section{Research Article}

Keywords: Risk evaluation, Slurry pressure, Propulsion speed, Embankment and subgrade settlement, Rough set theory

Posted Date: March 10th, 2021

DOl: https://doi.org/10.21203/rs.3.rs-268701/v1

License: (c) (i) This work is licensed under a Creative Commons Attribution 4.0 International License. Read Full License 


\section{Abstract}

Regarding the situation of slurry pressure shield tunneling underneath existing operating railway, traditional risk assessment method that takes the settlement risk of shield tunneling underneath the railroad as the evaluation objective cannot determine the risk development trend. Therefore, a shield tunneling underneath railroad risk evaluation model based on set pair analysis was proposed. First, according to the SPB shield construction mechanism, the risk source identification of the shield construction process was carried out, and the index factor system that leads to the settlement risk was formed. The importance of each evaluation index in the model was optimized by rough set, and then a five-element connection number model with objectively improved weights was obtained. Finally assessed the risk level of railroad settlement caused by the shield tunneling. This model is suitable for the actual construction of a subway shield tunnel, which is consistent with the results of the site survey, and has reference significance for the risk assessment of similar underpass projects.

\section{Full Text}

Due to technical limitations, full-text HTML conversion of this manuscript could not be completed. However, the latest manuscript can be downloaded and accessed as a PDF.

\section{Figures}

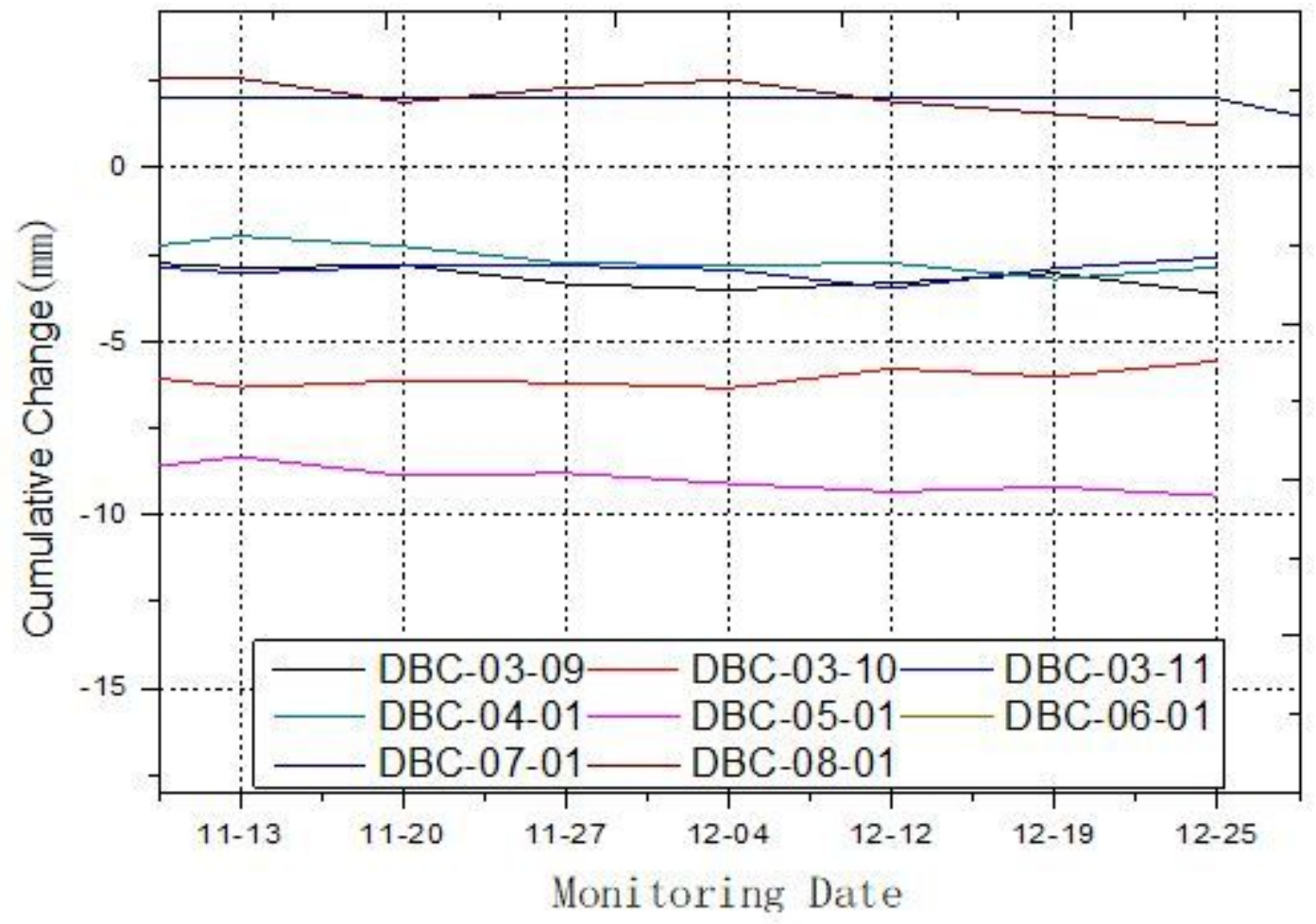

Figure 1

Time-history curve of ground settlement of monitoring points 